\title{
TRANSFORMACIÓN SOCIAL Y JUVENTUDES, UNA MIRADA A SUS TÁCTICAS Y ESTRATEGIAS ${ }^{1}$
}

\author{
* NATALiA HERNÁNDEZ MARY
}

\begin{abstract}
RESUMEN
En el presente artículo, tomo como prisma la noción de lo político para revisar las tácticas y estrategias que despliegan agrupaciones juveniles en pos de generar transformaciones sociales. Lo político es una categoría tensionada, ya que se construye desde diversos entendimientos. Se nombra, se vivencia, se experimenta, lo cual no garantiza que se historice. Posee una relación estrecha con la noción de «la política», convirtiéndose (en ocasiones) en su sinónimo. Su abordaje posibilita pensar los sitios desde donde agrupaciones juveniles construyen apuestas de transformación social.
\end{abstract}

PALABRAS CLAVE: LO POLÍTICO, ESTRATEGIAS, TRANSFORMACIÓN SOCIAL

1 Artículo basado en la tesis para optar al grado de doctora en Trabajo Social, «Poder, una categoría de análisis en los procesos de intervención de jóvenes: Estrategias de intervención en lo político», Universidad Nacional de La Plata, Argentina.

* Doctora en Trabajo Social, Universidad Nacional de La Plata, Argentina; magíster en Trabajo Social, Pontificia Universidad Católica de Chile; licenciada y trabajadora social, Pontificia Universidad Católica de Chile; diplomada en Mundos Juveniles, ACHNU-Universidad de Chile. Académica del Departamento de Trabajo Social, Universidad Alberto Hurtado, Santiago, Chile. Correo electrónico: nhernand@uahurtado.cl 


\title{
TRANSFORMAÇÃO SOCIAL E JUVENTUDES, UM OLHAR PARA SUAS TÁTICAS E ESTRATÉGIAS
}

\begin{abstract}
RESUMO
Neste artigo, utilizo como prisma a noção do político para revisar as táticas e estratégias que os grupos de jovens exibem para gerar transformações sociais. O político é uma categoria tensionada, pois é construída a partir de vários entendimentos. É nomeado, vivenciado, experiente, o que não garante que se torne histórico. Ele tem uma relação estreita com a noção de " a política", tornando-se (às vezes) em seu sinônimo. Sua abordagem torna possível o fato de pensar os lugares de onde os grupos de jovens constroem apostas de transformação social.
\end{abstract}

PALAVRAS-CHAVE: O POLÍTICO, ESTRATÉGIAS, TRANSFORMAÇÃO SOCIAL

\section{SOCIAL TRANSFORMATIONS AND YOUTHS:}

\section{A VIEW ON THEIR TACTICS AND STRATEGIES}

\begin{abstract}
The present article starts from a notion of "the political" in order to review the strategies and tactics displayed by youth groups to generate social transformations. The political is a category under tension, as it is constructed from diverse understandings; although it is named, lived and experienced, its historization is not guaranteed, and it is closely related to the notion of "politics", even becoming equivalent at times. By addressing this matter, it is feasible to think the places where youth organizations are building social transformation.
\end{abstract}

KEYWORDS: THE POLITICAL, STRATEGIES, SOCIAL TRANSFORMATION 


\section{INTRODUCCIÓN}

Lo político ha sido una concepción debatida desde diferentes líneas y posicionamientos teóricos, epistémicos y metodológicos (por mencionar algunos), brindando escenarios fructíferos para elaboraciones ideológicas y simbólicas, que sustentan discusiones en torno a su compresión. Lo anterior se relaciona con las diversas experiencias que las y los sujetos sociales desarrollan al incorporarla a sus trayectorias, ya sea como espacio de acción y/o como horizonte transformativo. Se reconoce, a la vez, un esfuerzo en generar la distinción con la idea de «política».

Discutir en torno a esta elaboración me invita a pensar en su operatividad en los espacios de transformación. Lo político se encuentra presente en los discursos $\mathrm{y}$ en las acciones de agrupaciones que se han comprometido en pos de transformaciones sociales. Esta constatación me permitió construir un cuestionamiento en torno a reconocer las estrategias y técnicas de intervención que desarrollan las y los jóvenes que se compromete con esta noción como fundamento y horizonte. Reconozco en las y los jóvenes una actoría situada entre los momentos vitales de sus trayectorias y las de una sociedad que se moviliza cotidianamente.

Reconocer las actorías juveniles se presenta como una dislocación a los multidominios que constituyen a las sociedades neoliberales. Hago referencia a las hegemonías que se aprecian en los ámbitos de clase, raza, género, edad, entre otros, los que provocan una opacidad constante y móvil, en torno a las existencias de sujetos sociales diversos y contemporáneos. Desde esos prismas, construir a las y los jóvenes desde actorías sociales se convierte en requisito para el quehacer de mi propuesta investigativa, ya que comparto la mirada en torno a la relación constante entre actores y sociedades. Es una tensión permanente, que no se agota en un momento histórico particular.

Juventudes y lo político no es una diada nueva. La encontramos presente en diversos campos de conocimiento (y del hacer), pero al tensionarla con la idea de estrategias de intervención, brinda una mirada situada de las transformaciones sociales que se construyen en asociaciones y/o agrupaciones que se proponen trabajar por ello, articulándose y/o incomodando a las propuestas hegemónicas que vienen dadas desde las líneas programáticas que asumen el abordaje de los cambios sociales.

Este artículo lo construyo a partir de mi investigación doctoral titulada «Poder, una categoría de análisis en los procesos de intervención de jóvenes: Estrategias de intervención en lo político», centrándome particularmente en el capítulo en que reviso las nociones que jóvenes de nueve agrupaciones elaboran en torno a las nociones de lo político y estrategias de transformación.

Dichas agrupaciones se ubican en la Región Metropolitana de Chile, que declaran trabajar en pos de cambios sociales que se ponen de manifiesto en espacios públicos e incluyen a diversos actores. La metodología que escogí para 
este trayecto fue la cualitativa. A través de esta apuesta combiné técnicas de entrevistas individuales y grupales, en las cuales utilicé la fotografía participante como disparador en estas instancias ${ }^{2}$. La elección se basó en la necesidad de dar cuenta de las tensiones entre los discursos, las acciones y las materialidades.

Trabajé con un análisis que me permitiera «un nuevo marco de aproximación empírica, como un método de análisis controlado del proceso de comunicación entre el texto y el contexto, estableciéndose un conjunto de reglas de análisis, paso a paso, que les separe de ciertas precipitaciones cuantificadoras» (Andréu, 2003: 22). Este análisis se funda en la posibilidad de generar interpretaciones de los textos, a partir de «dos grandes orientaciones: a) desarrollo de categorías inductivas y b) aplicación de categorías deductivas» (Andréu, 2003: 23). Esta opción se fundamenta en la posibilidad de construir categorías teóricas que fueran tensionándose con los elementos abordados desde el sistema de significados que los participantes desplegaron. Se toma un punto de partida, pero no se construye un recetario inmóvil, puesto que se «formulan a partir de la teoría, después se construye paso a paso todo un libro de códigos y categorías que se va aplicando al texto» (Andréu, 2003: 24).

Los tránsitos, los movimientos, las traslaciones, son los ejes donde ubiqué los engranajes que permiten la construcción de artefactos que aporten a revisar las estrategias y las tácticas que se manifiestan en los espacios cotidianos. La elaboración teórico-metodológica que he presentado posibilita comprender las nociones desde sus manifestaciones operativas y viceversa, ya que es en esta tensión donde se innovan las tácticas interventivas que las reúne.

En este texto brindo una discusión conceptual en torno a las nociones centrales, para relevar los hallazgos que construimos en este proceso, y las conclusiones que abren nuevas posibilidades de abordajes, aprendizajes y desafios en torno a las transformaciones sociales que se impulsan desde las actorías juveniles.

\section{JÓVENES Y ACTORÍA CONTEMPORÁNEA}

La construcción de las y los jóvenes ha sido una apuesta histórica, que los ha situado en diversas tensiones del Chile contemporáneo. Hemos transitado por negaciones constantes en torno a estos sujetos, como a una extrema valoración, ubicándolos como los responsables de edificar pilares societales que brinden un

2 El presente artículo abordará el material discursivo que trabajamos en las instancias de las entrevistas individuales y grupales. Para ello, se llevó a cabo un proceso de consentimiento informado con todas y todos los participantes. El material consta de nueve espacios grupales y veintiocho entrevistas individuales. Al momento de citarlos, he decidido nombrar al material grupal como «T» (con números respectivos) y a los individuales como «E» (con sus respectivos números). 
estatus de justicia social, que hoy se presentan como inalcanzables. Por ello, se les ponen en un tiempo y espacio que aún no se manifiesta, es decir, en el futuro (Duarte, 2015). El vaivén de dichas construcciones ha dificultado las posibilidades de repensar actorías sociales desde los momentos vitales que cada sujeto desarrolla.

Para este artículo me interesa dejar de manifiesto el reconocimiento de las y los sujetos jóvenes en un presente que se moviliza. No es mi interés dejarlos fijos, ni llenarlos de significados que los aten a un proceso particular. Construyo la noción de forma integral, de manera que se relacione con la tensión de los tejidos sociales globales y particulares. Reconozco, al momento de nombrar a las y los jóvenes, a sujetos sociales que se vinculan estrechamente con la construcción de espacios políticos, pues a través de sus trayectorias, vivencias y conjunto de creencias, movilizan trazados que les involucran tanto a ellas/os, como al resto de los integrantes de la sociedad. Asumo en su elaboración la heterogeneidad, diversidad, conflictividad, entre otros, ya que su presencia en los tejidos sociales es visible, es actual, es contemporánea. Todo sujeto se vincula con sus contextos, los modifica y a la vez, esos escenarios van constituyendo a los propios actores (Touraine, 2006).

De esta manera, abrazo como perspectiva de construcción aquella que conjuga elementos sociales y culturales, en donde el ejercicio de historización es un eje fundante para rescatar las experiencias de las trayectorias. Estos elementos se sitúan en un tiempo/espacio particular, lo que brinda prismas de comprensión en torno a estos sujetos sociales. Junto a ello, la apuesta que orienta este trabajo asume el desafío de lo plural y lo diverso, por ende, se hace cargo de la idea de juventudes, intentando desafiar la homologación que se ha realizado históricamente.

Desde ahí que relevo las significancias que movilizan a las y los jóvenes para constituirse en sujetos colectivos, que se agrupan desde las posibilidades que les brinda un horizonte compartido. La posibilidad de movilización desde las subjetividades se puede visibilizar en ámbitos individuales como en los espacios comunes que están constituidos por aquellos que llamamos públicos. Las agrupaciones ponen de manifiesto sus conjuntos de creencias, ideologías y nociones, en las relaciones que establecen con los otros distintos a ellos. Las acciones de disputa de las agrupaciones en los espacios políticos son de interés para revisar las estrategias que despliegan en estos escenarios (Hernández, 2018).

Comprender que las y los jóvenes se conforman (también) como sujetos colectivos, lo sustento desde la revisión de trabajos que provienen desde diversas disciplinas. Desde la perspectiva histórica se encuentran estudios que ha encabezado Víctor Muñoz (2010); aquellos de corte antropológico, como los de Óscar Aguilera (2014); las construcciones sociológicas desde los aportes de Claudio Duarte (2015), y trabajos de indagación en red (asociación de diversas instituciones universitarias), como el Anillo en Juventudes, que agrupa a 
investigadores expertos en la temática, entre ellos, Yadira Palenzuela (2018), Carolina Álvarez (2016), entre otros.

De esta manera, comprendo que las actorías juveniles se vivencian tanto desde lo individual como lo colectivo. Desde ahí que la idea de lo político se ha instalado como una construcción que se presenta como una posibilidad de tensionar la construcción de sujetos sociales, y las tácticas que despliegan desde un conjunto de decisiones discutidas, reflexionadas y planificadas, en los contextos en que se sitúan. Lo anterior se vincula directamente con la posibilidad de ser un testigo y actor de los movimientos sociales (Hernández, 2019).

Los escenarios contemporáneos permiten desarrollar una discusión en torno a la construcción de las juventudes desde las lógicas de la actoría social. Si bien dicha acción es reconocible en tensión con los diversos elementos que conforman los escenarios sociohistóricos, puede verse nutrida al momento de incorporar, en dicha construcción, el reconocimiento en torno a la posesión de poder social.

Estas construcciones integradas de las juventudes posibilitan visibilizar, en su elaboración, una apuesta que combina lo teórico, lo epistémico, lo contextual, lo valórico, lo cultural, lo histórico (entre otras dimensiones), en un movimiento constante, que permita dar cuenta de la diversidad de formas de vivir y habitar lo social. Son sujetos sociales que poseen características específicas en torno a su momento vital, las cuales se tensionan con las demandas societales. Estas intersecciones son las que dan bases culturales para sus apuestas ideológicas que se movilizan desde lo individual a lo colectivo, y viceversa. Juventudes es teoría, poder y política en el aquí y ahora.

\section{LO POLÍTICO, UNA DISCUSIÓN SITUADA}

La idea de transformación que menciono se vincula con las discusiones que se han alojado en las ciencias sociales, como un escenario de debate y preocupación en torno a las construcciones de justicia social que se requieren en estos contextos. Si bien existen diversas comprensiones, asumo como línea de pensamiento aquella que congrega en su constitución las relaciones de poder entre micros y macros espacios, afectando los vínculos sociales entre sujetos y estructuras (Foucault, 1979).

Desde las propuestas críticas de la intervención social, es posible relevar que la construcción del sujeto en cuestión cobra un desafío particular, puesto que, en dichos procesos, se posesionan las posibilidades de velar por las complejidades que los procesos requieren. La cuestión acá es que «el otro» puede contingentemente adoptar las características dadas por quien lo mira y lo busca nombrar. Y si bien a un otro, subordinado, jerarquizado, se le puede conceder alguna virtud estética o moral, muy difícilmente se alcanzará un estatuto de legítimo pensamiento (Hernández, 2018). Asimismo, desde esta expresión de un 
régimen de la mirada sobre el otro, se construye una serie de imaginarios socioculturales:

En la complejidad existente, la interrogante sobre el modo de nombrar al otro se relaciona, a su vez, con un discurso sobre el valor y la ética, con la pregunta acerca de cómo se apela al valor y a la posibilidad del otro en una sociedad diferenciada. (Agnes, 1990: 78-79)

Elaborar concepciones integradas (a las nociones de juventudes y actorías) releva las opciones de interactuar con sujetos integrales, y no con aquellas visiones que se constituyen desde la estigmatización deficitaria. Genera un desafío constante, en cuanto a los mecanismos de acercamiento, puesto que posibilita finiquitar aquellas tensiones contradictorias que los visualizan desde posiciones dominadas, las cuales se centran en lógicas anulantes, que conllevan a una invisibilización permanente. Posibilitan reconocerles desde procesos coherentes que son posibles de incorporar en diversos espacios sociales, aunando miradas en pos de complejizar los procesos de intervención que se diseñan constantemente.

Que lo político trascienda lo institucional posibilita un conjunto de elaboraciones que se vinculan a «otras formas» de comprender lo relacional y sus expresiones. Surge la idea de entenderlo como posibilidad privilegiada de abandonar las ideas de «un fundamento último», cuestionando las nociones hegemónicas, en donde se le reconoce como el escenario de visibilidad de la institucionalidad social. Así, es necesario revisar y analizar las débiles fronteras entre lo social y lo político, puesto que son inestables, ya que exigen para sí desplazamientos y renegociaciones constantes entre los actores sociales (Mouffe, 2007).

Se da cabida a la idea de disenso y conflicto, procurando apartar valoraciones negativas (desde las socializaciones hegemónicas) que los han acompañado en sus constituciones. Aquí, es posible reconocer el disenso como una posibilidad de construcción y reconstrucción de ciudadanías que se potencien en pos de un bienestar individual y colectivo (Hernández, 2019: 48)

Por ello, esta elaboración de «lo político» posibilita cuestionar aquello que ha sido entendido como el «orden natural» de la institucionalidad y de la política clásica, organizando la existencia humana, que es en sí misma, conflictiva (Mouffe, 2007).

Mirar lo político como este escenario que se construye desde tensiones, disensos y apuestas de entendimiento, sin que se invisibilicen las particularidades y las diferencias, posibilita que se construya un tejido diverso que disloque la 
idea de lo dual mayoría/minoría, posibilitando el reconocimiento y valoración por lo heterogéneo. Brinda opciones innovadoras que nos inviten a terminar con acciones que tienen sus raíces en lo conocido, pero no necesariamente, en lo que se valora y requiere para transformaciones actuales.

Dichas complejidades develan estrategias interventivas que se desprenden desde un sinfín de operatorias. Se despliegan desde lo conocido, lo aprendido, lo validado, pero también, desde aquellos aspectos que vienen a cuestionar justamente ese origen reconocido. Este conjunto de acciones (estrategias), que escapan de las convenciones conocidas, en ocasiones, no son valoradas. Lo distinto puede traer consigo un esplendor particular, el cual produce atracción, contemplación, como también miedo y desconfianza (por nombrar algunas sensaciones). Por lo tanto, revisar tácticas en lo político que se alejen de los patrones tradicionales provoca que los mundos adultos se tensionen, y elaboren (en ocasiones) desvalorizaciones, negaciones e invisibilizaciones. Ejercicios que suceden cuando pensamos los mundos juveniles desde el adultocentrismo ${ }^{3}$.

En los escenarios actuales, las agrupaciones juveniles asumen como un eje particular las acciones que se desplieguen desde la participación de todos los miembros de estas. Se valora el trabajo desde las bases y/o asambleas, fortaleciendo las ideas de lo comunitario. Una representatividad asignada o designada se aleja de los contextos contemporáneos, lo cual genera procesos de negociaciones, discusiones y reflexiones, que requieren tiempos, lugares y estrategias acordes a estas inspiraciones.

Los horizontes de transformación con los que se comprometen las acciones en lo político se acompañan de un discurso interesante en pos de los tipos de relaciones que se esperan construir en sociedades transversalmente inclusivas, comprometidas con los derechos sociales y elaboradas desde las lógicas de disenso. Sin embargo, estos discursos han sido cuestionados (e incluso atacados) desde espacios de análisis de corte más conservadores, que los tildan de «populistas», con la intención de construirlos como una respuesta verbal (discursos políticos) sin capacidad de concretizarse, y, por ende, se les estigmatiza como una acción estratégica para captar simpatizantes en el resto de la sociedad (Hernández, 2018).

Lo político se articula con las nociones de juventudes y poder, como parte de un engranaje que se moviliza desde los reconocimientos de diversas actorías sociales, desplegando múltiples estrategias de transformación, las cuales no niegan las tradiciones, pero sí son capaces de revitalizarlas en pos de los escenarios en que las acciones se despliegan.

El engranaje que menciono se convierte en un motor particular para revisitar, diseñar y operacionalizar transformaciones que se sostienen desde la diferencia, el disenso y los conflictos. Las estrategias que se despliegan desde estas nociones

\footnotetext{
${ }^{3}$ Tomo la noción de adultocentrismo desde los trabajos de Claudio Duarte.
} 
asumen como clave la tensión constante de los diversos elementos que se ven involucrados.

\section{ESTRATEGIAS DE INTERVENCIÓN DESDE EL PRISMA DE LO POLÍTICO}

A continuación, presentaré cómo lo político se constituye en un prisma de observación para revisar las tácticas y estrategias de las organizaciones juveniles. La invitación a pensar en lo político generó una expectativa particular en las y los participantes (en todas las instancias del trabajo de campo), debido a lo común que se les hizo la noción, en un primer momento.

Todas las agrupaciones juveniles declaran participar en este espacio en pos de transformar condicionantes sociales que no son justas para las y los actores que la constituyen. Han desarrollado discusiones en torno a las ideologías que impulsa su participación $\mathrm{y}$, por ende, asumen posturas relacionadas $\mathrm{y} / \mathrm{o}$ coherentes con lo que han definido.

$\mathrm{Al}$ invitarlas a trabajar con las nociones en torno al concepto, se provoca una confusión en relación con la idea a la que se desean referir. Algunos asumen que «lo político» es sinónimo de «la política», lo que les dificulta el ejercicio de elaborar una conceptualización diferenciada para cada noción. Desde esta tensión aparecen ejercicios de asociación de los conceptos. Presentan un vínculo entre «la política», con la institucionalidad del Estado, y las relaciones que surgen desde estas instancias. La política aparece como parte de un sistema que es necesario para la construcción de gobiernos.

El abordaje de «lo político» se hace desde un nivel micro, relacionado con las formas de construir los idearios de sociedad desde la propia organización, como también con aquellos espacios que permiten el encuentro, lo común, lo público.

En cuanto a su operatoria, ambos términos son asociados a las ideas de estrategias, tácticas, planificaciones, entre otras. Dichos ejercicios se visibilizan desde las opciones del diálogo común, el cual considera al todo de lo social, como también, desde acciones que responden a requerimientos individualistas $\mathrm{y} / \mathrm{o}$ de grupos específicos.

El interés por construir la diferencia entre las nociones es una dimensión que emerge desde las instancias de la investigación. Es por ello que la construcción de este prisma lo iniciaré con un movimiento de traslación entre los dos conceptos, intentando dar cuenta de la vinculación que las y los participantes realizan.

En una primera aproximación, la política es comprendida como ejercicio asociado a la participación en la toma de decisiones del sistema democrático. Las y los participantes reparan en un punto de encuentro entre la idea de «política» 
con los sistemas de gobierno. Aquí se aprecia un vínculo con imágenes que reflejan formas de operacionalizar (la idea de acuerdos tradicionales) una gobernabilidad de carácter democrático. Identifican que la noción de política trae consigo la herencia de gobierno; incluso se hace referencia a cómo cierta elite es la que ha podido tener acceso a esta dimensión, gobernando el país desde esa lógica. Comentan que es una «cuasi» tradición republicana comprender que «solo» algunos son los que pueden estar en política, decidir e incluso enriquecerse:

Yo creo que en Chile hemos creído por mucho tiempo que la política es tierra de algunos, de los que deciden, de los que están en partidos, los que se pelean, los gobiernos (...) política es para los «señoritos». (E17)

Ahora, la mirada que definen como histórica, tradicional y/o clásica, es tensionada con visiones que aparecen en las conversaciones entre las y los participantes. Esas miradas retoman las nociones que se elaboran desde los procesos eleccionarios y las construcciones realizadas por un grupo generacional que no se acerca a los planteamientos e ideologías que actualmente sostienen.

De esta manera, la política también es entendida como fuerzas para generar transformaciones y como poder de decisión. Indican que estas nociones se comprenden siempre y cuando se reconozca desde la tensión entre lo individual y lo colectivo.

La política es un término contaminado y mal usado, como de una elite, expertos que llegan al poder tradicional (Estado), pero hoy vemos con fuerza una nueva política, los movimientos sociales. (T PI4)

Junto con la generación de nuevas posibilidades sociales, la política es identificada como un escenario de disputa constante. Construyen la concepción como una lucha cotidiana de las relaciones de poder, en la cual, la acción política se configura desde sus actos políticos, por medio de acciones del diario vivir, como también en las escenas masivas, con el fin de influir y generar cambios a distintos niveles, disputándoles poder a las instituciones. La idea de poder que aparece ligada a esta disputa se relaciona con las posibilidades de reconocer nuevos ordenamientos de lo social, rompiendo la inercia que está dada por «la» forma tradicional que se ha heredado.

Como se indicaba, esta herencia está muy ligada a tradiciones estructuradas desde un modelo particular de sociedad chilena. Se vincula a un sistema de mercado (que en sí mismo es una hegemonía poderosa), como también a las formas de ordenamiento que se relacionan con este capitalismo «duro». Las discusiones entre las y los participantes se desarrollan en forma espiral, en donde 
indican que la política ha estado al servicio de este mercado y, por ende, la apuesta en torno a los derechos humanos, el cohabitar, ha estado lejos del sistema imperante.

La relación entre mercado, capitalismo, política y estructuras sociales apareció constantemente; lo que varía es la valoración que se les asigna a estos vínculos y las formas de comprender las transformaciones que se pueden potenciar desde estas relaciones. Las posibilidades de cambios desde los espacios que brinda «la» política son reconocidas por todas las agrupaciones, con las salvedades necesarias en pos de la ideología que constituyen los proyectos sociopolíticos en que se encuentran representados.

Desde este prisma, se abre una arista crítica que aborda las posibilidades de deconstruir la idea de «política» como sistema y abordar la idea de «lo» político como una categoría que diferencie los sentidos. Nombrar desde la idea de «lo» brinda posibilidades de problematizar las reflexiones que construyen desde los contenidos históricos que abordan. Cristalizan en ella la idea de transformación, lo comunitario, lo plural, lo diverso y la idea constante de la disputa de relaciones de poder.

Se puede ver como un acto súper chico ir con un arco y pararse delante de un paco al frente de La Moneda, pero todos hacemos política, un acto político es desde lo más pequeño hasta cortar Tocopilla o cortar Chiloé... un acto político es una manifestación, es una expresión de lo que siente, de lo que se crea, y también tiene poder que se disputa, sobre todo con las instituciones. (E 24)

La idea de «lo» político supera a la noción de «la» política, especialmente al revisarlo desde las expresiones de cada sujeto social en los espacios comunitarios. Se plasma en una acción concreta que busca transmitir, a y con otros, las apuestas propias de un sujeto y/o colectivo. Para ello, el eje central no está puesto necesariamente en lo masivo, sino en los entramados que se elaboran en comunión con otras y otros, que se comparten, que se visibilizan. Aparece la idea de lo público como una bisagra elemental.

Es que hay que entender que lo político no es solo el Congreso, la sala tanto, el diputado tanto. Eso no es todo lo político. Lo político no se encierra en La Moneda. Nosotros llevamos una vida llena de actos políticos, un montón de decisiones. (E 6)

Las acciones que se ponen de manifiesto se sustentan en las propuestas que se construyen desde espacios particulares, que reúnen una conjunción de posibilidades, de inquietudes y de apuestas diferenciadas. Se asocia a impulsos concretos de transformar aquellas incomodidades que no han surgido desde lo 
decidido, sino que se han sustentado desde creencias, estructuras e ideologías naturalizadas por contextos que no responden necesariamente a las condiciones actuales. Lo político está estrechamente ligado a la idea de transformación.

Es como el tema de la hegemonía de Gramsci. No sacamos nada con cambiar las leyes si no cambiamos la cultura del país. Claramente le podís llamar educación. Tiene que ver con generar incidencia e ir cambiando el sentido común. (E 6)

Porque está al debe la transformación de lo político (...) todas las deudas que existen con este pueblo y que desde lo político siempre se ha ido trabando y se ha tendido a maltratar. (E10)

Hay un reconocimiento y entendimiento que se basan en las miradas del sistema político, por ende, es reconocido desde las tradiciones de los partidos políticos, los gobiernos de turno y las construcciones que genera la política en las relaciones sociales. Al mismo tiempo, es posible reconocer un discurso que busca diferenciarlo de estas tradiciones. Se construye una idea que da cuenta de lo público, de los actores habitando espacios comunes, integrativos. Por ello aparecen como imágenes para hablar de lo político, todas aquellas que ilustran espacios cotidianos, abiertos, instalados en diversos espacios, más allá de una georreferenciación clasista. Lo político, al mismo tiempo «es» y «se construye» por todas y todos.

Las elaboraciones transitan, se mueven, se combinan. Las y los participantes reconocen que esta noción se construye a partir del movimiento constante entre nociones heredadas y aquellas que han nacido desde las discusiones actuales. Cabe decir que estas instancias de reflexión se nutren desde los elementos teóricos revisados, las experiencias vividas, la historización de los procesos, entre otros que se movilizan en un mismo tiempo y espacio.

Es para mí relevante indicar que las y los participantes no llegan a una definición única, ni buscan posicionarse desde una postura particular. A través del dispositivo construido se me hace posible identificar el movimiento como parte central de sus apuestas de abordaje, ya que no se rompe una idea fija, más bien, se utilizan, se actualizan, en pos de los impulsos que detonan en los procesos que las agrupaciones promueven.

El movimiento constante, la construcción de la noción de lo político, permite a su vez que se readecúen herramientas, tácticas y estrategias a favor de los horizontes que se trazan para una sociedad distinta.

En el espacio en que se discuten las nociones entre la política y lo político, surge un vínculo con las formas en que se construye e impulsa la organización social. Lo político entiende lo público como eje central para su vivencia 
cotidiana, lo que permite que se vincule con formas de participación que generen posibilidades de elección.

Entonces, lo cotidiano pasa por las decisiones en torno a «cómo» se organiza esto de lo público desde las experiencias de relación con otros. La agrupación revisa sus formas de organización y las instancias de vinculación que sostiene con su contexto. Reconocer sitio, actores y momentos permite definir cómo la organización define apuestas por lo común.

Hoy día se están organizando, hemos conformado más de siete nuevas organizaciones juveniles y, por lo mismo, ellos se están dando a notar. Acá estamos nosotros presentes y queremos opinar, queremos participar y ser parte de algo tomando la iniciativa. (T8)

La política, a su vez, denota cuestionamiento, una crítica social que está en constante evaluación de las lógicas gubernamentales. Es una apreciación que permite generar injerencia en dicha estructura. En consecuencia, para ejercer actos de participación, los sujetos políticos deben tener conciencia de lo que están realizando, y sus actos deben ser ejercidos de forma voluntaria. Es aquí donde la noción de lo político asume para las y los entrevistados una significancia particular, pues logra tomar aquellos elementos que ya se han mencionado en el escenario de lo común, lo compartido y lo que se considera como parte de todas y todos. Esta comprensión moviliza y explica las capacidades, fuerzas, diferencias, que se ponen en tensión en los espacios públicos, que tiene como requerimiento la decisión por parte de los sujetos, y les ofrece un repertorio para concretizar las acciones sociales y políticas, que los motiva en pos de transformaciones.

La movilización individual y colectiva es la que lleva, de alguna manera, a generar este cuestionamiento, esta crítica social, que tienen las personas respecto al género, a las funcionalidades de que se nos otorgan desde lógicas gubernamentales, inclusive. (T2)

Las posibilidades que brinda la idea de lo político acogen en su sentido las posibilidades para el diálogo y los disensos. Las y los jóvenes participantes de esta investigación, relevan esta posibilidad como crucial para el desarrollo de las apuestas ideológicas que movilizan sus actos en sus espacios de acción.

Reconstruyen, como sentido inicial, la idea de encontrase y debatir en torno a las apuestas de sociedad que visualizan. Desde el acto de encontrase desde sus diferencias, generan y valoran tácticas específicas para construir nuevos discursos, nuevos debates y acciones que requieren una interacción de fuerzas. 
A través de las tácticas se convierten en parte de los contextos y, por ende, con lo histórico.

Las posibilidades de diálogo conllevan para las organizaciones juveniles un escenario con condiciones mínimas que garantice que suceda. Indican que se deben generar una deconstrucción de lo público, de tal manera que las y los sujetos sociales se sientan partícipes de él. Es un escenario que se construye en pos de reconocer la diferencia, las distintas significancias y las ideologías. Agregan que es un proceso de construcción que requiere acuerdos organizativos entre todos los que se sienten convocados, desde ahí que las tácticas en pos de reconstruir lo público como eje de lo político cobra un valor particular y único, pues para ellas y ellos implica historizarlo.

Yo creo que lo político es asumir que, mmm, por ejemplo, que la Alameda es de todas y todos... no de algunos... o sea, llegar a La Moneda cuando marchamos, no es porque se nos ocurrió, sino que es parte de nosotros po', es historia, no pueden volver a quitárnosla como lo hicieron pal golpe... No sé si me explico... pero es un espacio común, compartido, de todos po'. (E 26)

\section{RECONSTRUIR LO POLÍTICO EN RELACIÓN CON LAS ESTRATEGIAS DE INTERVENCIÓN}

Entender que las estrategias de intervención son un conjunto de convenciones que se tornan visibles a través de distintas acciones sociales posibilita desplegar aprendizajes.

Lo político toma la forma de un caleidoscopio, nos permite tensionar los ejes de comprensión que estamos desplegando para mirar los escenarios actuales y las posibles transformaciones que se pueden generar desde ahí.

Es innegable que existen confusiones entre lo político y la política, se usan como sinónimos, sin embargo, las políticas se asocian mucho más a las formas de gobierno. Entonces, cuando uno habla de lo político, se cree que se está hablando de un gobierno desde las posiciones partidistas, asociándolo a las elites de Chile. No todos podemos gobernar, son algunos pocos, son los que tienen acceso. Esa afirmación moviliza a las agrupaciones para desplegar alternativas que nos saquen de esa dualidad. Se quiere participar, se quiere estar presente, pero desde las propuestas que se sitúan en las significaciones y elaboraciones que las actorías juveniles desarrollan.

Entonces, ¿qué pasa? La política es una construcción que rechazo, pues ella me rechaza como actor juvenil, ya que no está validando ni trabajando por los derechos que yo estoy luchando. En esta tensión lo político se asocia a lo público, ya que se liga a la idea de transformación y, por ende, se entiende que (lo 
político) es un espacio de disputa, donde los derechos tienen que tomar esta voz cantante en cuanto a la construcción de todas y todos.

Ahora, desde ahí, la idea de transformación, de lo comunitario, lo plural, lo diverso y el disenso aparece ligada a lo político. Es una elaboración que se constituye en un todo entretejido, la política toma una posición distinta, necesaria, en tanto brinde espacio a las subjetividades que se plasman en demandas diversas, las cuales no se dirigen únicamente a los sujetos jóvenes, sino que a todo el espectro de lo social.

Se está dislocando, se está apostando por otros espacios, lo que implica fomentar (y potenciar) transformaciones que son culturales, relacionales, e incluso teóricas. Las agrupaciones están haciendo su propio andar, y lo interesante es que desde aquí nos invitan a hacernos parte, nunca se han cerrado a una sola forma o a ciertos actores. Desde ahí que hay una invitación que se tensiona y aparece un concepto que yo no había trabajado en el caleidoscopio al inicio, que es la idea de participación, pues lo político es participación también.

La participación es la salida a la calle, la manifestación, como también es un vínculo entre el poder y lo político, donde la idea del conflicto tiene que instalarse. Dejar de sentir miedo a ese conflicto, a disputarlo. Esta relación se convierte en clave de participación y, por tanto, es una disputa constante.

RECIBIDO: 25 DE NOVIEMBRE DE 2019

ACEPTADO: 2 DE DICIEMBRE DE 2019 


\section{BIBLIOGRAFÍA}

Aguilera, O. (2007). «Movidas, movilizaciones y movimientos. Cultura política y pública de las culturas juveniles en el Chile de hoy». Tesis doctoral. Universidad Autónoma de Barcelona, España.

Aguilera, O. y MuÑOz, V. (2015). «Preguntas por la juventud, preguntas por la política. Acción colectiva, movimientos sociales y militancia en los estudios de juventud. Chile 1967-2013». En P. COTTET, Juventudes. Metáforas del Chile contemporáneo (pp. 69-103). Santiago: RIL Editores.

Álvarez, C. (2016). Juventudes en Chile. Miradas de jóvenes que investigan. Volumen 1. Santiago: Social Ediciones, Facultad de Ciencias Sociales de la Universidad de Chile.

ANDRÉU ABElA, J. (2000). «Las técnicas de análisis de contenido: una revisión actualizada». Fundación Centro Estudios Andaluces, 10(2): 1-34.

DUARTE, C. (2015). «El adultocentrismo como paradigma y sistema de dominio. Análisis de la reproducción de imaginarios en la investigación social chilena sobre juventud». Tesis doctoral. Universidad Autónoma de Barcelona, España.

Foucault, M. (1979). Microfisica del poder. Madrid: Las Ediciones de la Piqueta.

HERNÁNDEZ, N. (2019). «Lo político en disputa. Una mirada desde las juventudes». En Juventudes en Chile. Miradas de jóvenes que investigan. Volumen 2. Santiago: Social Ediciones, Facultad de Ciencias Sociales de la Universidad de Chile.

. (2018). «Poder, una categoría de análisis en los procesos de intervención de jóvenes: Estrategias de intervención en lo político». Tesis doctoral en Trabajo Social. Universidad Nacional de La Plata, Argentina.

Mouffe, C. (2007). En torno a lo político. Buenos Aires: Fondo de Cultura Económica.

PALENZUEla, Y. (2016). «Imaginarios sociales de jóvenes universitarios sobre su participación ciudadana en redes sociales virtuales». Juventudes en Chile. Miradas de jóvenes que investigan. Volumen 1. Santiago: Social Ediciones, Facultad de Ciencias Sociales de la Universidad de Chile.

TOURAINE, A. (2006). Un nuevo paradigma para comprender el mundo de hoy. Buenos Aires: Paidós. 